SEÇÃO EXTRA

ENTREVISTA

\title{
ENTREVISTA COM A PROFESSORA ANA LUCIA DE LYRA TAVARES
}

José Ribas Vieira

Professor Titular da

Universidade Federal

do Rio de Janeiro,

Rio de Janeiro, RJ.

jribas@direito.ufrj.br

\section{Deo Campos Dutra}

Professor da Faculdade

Doctum, Juiz de Fora, MG.

deo_campos@yahoo.com.br
Ana Lucia de Lyra Tavares é Professora Assistente da Pontifícia Universidade Católica do Rio de Janeiro, Rio de Janeiro, RJ, Brasil.
1. O Direito Comparado é considerado uma área que desperta o interesse de juristas naturalmente curiosos. Como você entende essa afirmação?

R. Reporto-me ao que usualmente acontecia, há mais de 40 anos atrás, quando a disciplina começou a ser ministrada na graduação do Departamento de Direito da PUC-Rio, em caráter eletivo. $\mathrm{Na}$ orientação para a matrícula, os professores encarregados dessa atividade, eram indagados pelos alunos sobre o significado da expressão "Direito Comparado". O que se comparava, com que se comparava, era um cotejo do direito brasileiro em relação ao estrangeiro? A curiosidade era sanada na primeira aula, durante a qual se explicitava que o Direito Comparado visa comparar os sistemas jurídicos entre si, seja em seu sentido amplo, de famílias de direito (como a romano-germânica e a de "common law") seja em sua acepção restrita de ordenamentos jurídicos nacionais. $\mathrm{O}$ direito brasileiro pode ser, mas não obrigatoriamente é claro, um dos termos da comparação. A essa natural curiosidade discente some-se aquela dos docentes, particularmente os brasileiros, que, de regra, se interessam pelas experiências jurídicas estrangeiras, embora nem sempre empreendam estudos de 
Direito Comparado, isto é, de efetivo cotejo de normas, institutos, princípios entre sistemas jurídicos diversos. Concentram-se, antes, na descrição do direito estrangeiro, chegando a uma justaposição, mas não a uma efetiva comparação. Esta comparação pressupõe a identificação de semelhanças e diferenças em torno de determinados aspectos básicos (a que chamamos de variáveis). As diferenças, como prelecionava o eminente comparatista René David, nunca são gratuitas. Há sempre uma justificativa para elas. Penso que a curiosidade integra a natureza do pesquisador de qualquer área. No caso do Direito Comparado, ele oferece um rico manancial de elementos para alimentá-la constantemente.

2. Como foi seu caminho até a docência na PUC Rio e na pósgraduação em Direito? A sua formação em Direito Romano influenciou este caminho?

R. Nossa turma de 1967 da PUC está completando neste final de ano 50 anos de formada. Como passaram rápido! Não havia pensado, até então, em ser professora de direito. Em 1966, fiz concurso para o então Estado da Guanabara para ministrar aulas de francês, pois havia finalizado o curso da Aliança Francesa. Em 1970, tive a oportunidade de cursar o doutorado na França. Aconselhada por um ilustre advogado e amigo, Ronaldo Borgerth Teixeira, inscrevi-me no curso de Direito Comparado da Universidade de Paris II. Ao retornar, fiquei trabalhando na antiga Escola de Serviço Público do Estado da Guanabara (ESPEG). Com o doutorado já revalidado, após o exame da tese que tratou de um estudo comparado sobre o Estado e o direito à educação na França e no Brasil, avaliação esta empreendida por uma comissão indicada pelo Conselho Federal de Educação, integrada pelos Professores Pedro Calmon, Afonso Arinos e Haroldo Valladão, continuava a trabalhar na ESPEG, local em que, por obra do destino, reencontrei o meu antigo professor de direito romano na PUC, o saudoso Professor Vicente Sobrino Porto. Sabedor do meu doutoramento em Direito Comparado, ele me levou para a PUC, em 1976, ano em que a cadeira foi introduzida em nível de gradução. Em 1982, o Professor Celso Duvivier de Albuquerque Mello, também meu antigo professor, ciente de que eu era pesquisadora de Direito Constitucional comparado na Fundação Getúlio Vargas, desde 1977, para aonde fora levada pelo meu antigo Professor Themístocles 
Brandão Cavalcanti, propôs o meu nome para ensinar essa disciplina na pós-graduação do Departamento. Sobressaem dessas indicações, que não houve, de minha parte, diversamente do que ocorre com muitos, um planejamento de etapas e de experiências para um preparo em vista da comparação no campo do direito. As circunstâncias favoráveis se apresentaram e eu procurei aproveitá-las da melhor forma, obviamente, dentro de minhas motivações e preferências e ciente de que nada é por acaso. Assim, o direito romano, matéria que viria a lecionar durante cerca de 13 anos, na graduação da PUC, ao mesmo tempo em que prosseguia no magistério do Direito Comparado, reapareceu na minha vida, como recordei acima, na pessoa do Professor Vicente Sobrino Porto. Não estabeleci, pois, uma meta de me aprimorar primeiro no direito romano para, em seguida, abordar o Direito Comparado. Aconteceu o contrário. Foi a partir do estudo da família romano-germânica e do das recepções do direito romano em vários sistemas jurídicos que despertei para a necessidade de aprimorar as minhas investigações nesse campo. Indagada pela professora Celina Bodin de Moraes, então Diretora do Departamento de Direito da PUC-Rio, se gostaria de ministrar, na graduação, aulas de Direito Constitucional ou de direito romano, não hesitei em escolher este último. Esta escolha mostrou-me novos ângulos de pesquisa no Direito Comparado. De qualquer modo, seja por um caminho de circunstâncias pessoais, seja por via de planejamento, é inegável que a interação dos estudos de direito romano e de Direito Comparado é fundamental.

\section{Quais juristas a senhora sempre procura acompanhar a pesquisa e produção?}

R. Há alguns pressupostos a serem aqui considerados. Por um lado, os estudos comparativos no campo jurídico requerem uma grande abertura nas fontes de pesquisa, sem a eleição prévia de um determinado autor ou grupo linguístico. É esta abertura que favorece o conhecimento mais exato de experiências jurídicas estrangeiras, sem um olhar que condicione a nossa análise, ocultando, por vezes, aspectos fundamentais para a compreensão do contexto pesquisado. Por outro lado, é natural que privilegiemos a leitura nos idiomas que nos sejam mais familiares. $O$ aconselhável é o conhecimento do maior número possível de idiomas estrangeiros, para evitar 
a dependência das traduções. Há que se ter, em conta, também, outros ângulos. Um deles é a perspectiva que o pesquisador está privilegiando. Se se buscar o conhecimento dos aspectos gerais da disciplina, há certos nomes de referência obrigatória, antigos e mais recentes, tais como Edouard Lambert, Gutteridge, Mario Rotondi, Wahlendort, Zweigert, Rodolfo Sacco, René David, Rheinstein, Merryman, enfim, uma plêiade de juristas. Se se enveredar para o campo da metodologia do Direito Comparado, tem-se que verificar se se trata de estudo dos seus aspectos teóricos, ou de um levantamento de experiências da comparação jurídica. No meu caso, mais do que as indagações teóricas sobre a metodologia do Direito Comparado, procurei autores que me norteassem na prática efetiva da comparação no direito e nos estudos de circulação de modelos jurídicos. Para tanto, nomes como os de René David, Mauro Cappelletti, Marc Ancel, Constantinesco, Papachristos atraíam, de pronto, a minha atenção. Outro ângulo a direcionar as escolhas bibliográficas é o próprio ramo do direito objeto da comparação, que requer indicação específica dos elementos a serem cotejados, o que leva muitos mestres de disciplinas específicas a desenvolverem destacados estudos comparativos. Por exemplo, o Direito Constitucional comparado tem os seus autores consagrados, como Di Ruffia, Giuseppe de Vergottini; no direito civil comparado, dependendo da parte analisada, avultam outros autores. É o caso de André Tunc, na esfera dos estudos de responsabilidade civil. No Brasil contemporâneo, temos ilustres comparatistas especialistas de determinadas áreas jurídicas, como: os Professores Arnold Wald e a Professora Véra Fradera, da UFRGS, no direito contratual comparado; o Professor Ivo Dantas, no Direito Constitucional comparado; o Professor Francisco Amaral, nas diversas partes do direito civil. E, anteriormente, o Professor Caio Mario da Silva Pereira, o Professor Raul Machado Horta, o Professor Haroldo Valladão, e tantos outros mestres.

\section{Se a senhora pudesse escolher algumas obras (literatura jurídicas} e não jurídicas) que mais a influenciaram, quais seriam?

R. Sem prejuízo das reflexões acima, é natural que, no campo do Direito Comparado, geral e específico, como também no do direito romano, em sua interação, com o Direito Comparado, certas obras sejam primeiramente consultadas, sem prejuízo da necessária 
abertura para outras fontes de pesquisa, incluindo os periódicos da área. Destacaria, então: os Grandes Sistemas de Direito Contemporâneo, de René David; a utilidade e o método do Direito Comparado, de Marc Ancel; a consulta regular ao Tratado de Ciência Política de Georges Burdeau; direito flexível, de Jean Carbonnier, a Tradição da Civil Law, de Merryman; Legal transplants, de Alan Watson; A Europa e o direito romano, de Koschaker. Em plano geral jurídico, menciono os estudos de Lord Denning, de Georges Ripert, de René Savatier. Em nível não jurídico, aficcionada que sou da literatura francesa, "As cartas persas", de Montesquieu, os ensaios, de Montaigne, as obras de Flaubert. Estou tentando, agora, retomar a leitura de certos livros que foram apenas percorridos durante a vida acadêmica ativa, como os pensamentos de Pascal. Por outro lado, destaco estudos clássicos sobre o Brasil, infelizmente ignorados hoje, como é o caso de Bandeirantes e Pioneiros, de Vianna Moog, os de Silvio Romero. Ainda em plano não jurídico, tenho procurado ler e reler livros da doutrina e da prática católica. Retornei aos textos de Jacques Maritain, de Gustavo Corção, de Henri Nouwen, de Inácio Larrañaga. Atualmente, estou procurando ler os livros de Thomas Merton, monge beneditino americano, interesse despertado a partir de um seminário promovido pela PUC-Rio, e, sobretudo depois que tive a chance de poder fazer um retiro promovido pela Sociedade dos Amigos de Thomas Merton, pregado por Dom Bernardo Bonowits, também monge beneditino e Abade do Mosteiro Nossa Senhora do Novo Mundo, no Paraná. Ele tem uma história atípica, pois é americano e era judeu, tenho sido batizado aos 19 anos. Vale acompanhar na internet as suas entrevistas.

\section{SALA DE AULA}

1. O termo "Direito Comparado" já teve seu conceito e sentido como objeto principal das reflexões de grande parte dos diversos autores que trabalharam neste campo do direito. Ainda hoje parece haver um verdadeiro "fetiche " em discutir o tema, assim como a questão da metodologia. Para a senhora, este debate já está superado, ou não? Na sua concepção qual seria o sentido que o termo "Direito Comparado" possui?

R. A partir do momento em que se esclareça que o Direito Comparado visa ao cotejo de sistemas jurídicos, espacialmente e mesmo 
temporalmente distintos, numa acepção macro (de grandes famílias de direito) ou num enfoque micro, de ordenamentos jurídicos nacionais) ,como ressaltado na primeira resposta, considero que o prosseguimento da análise sobre o significado do termo perde muito do seu interesse, não obstante as reflexões de valor teórico que ele possa suscitar. Em relação à questão da metodologia do Direito Comparado, tão em voga, há um estudo do Professor Uwe Kischel, assistente do eminente Professor Drobnig, do Max Planck Institute que traça, com precisão, o quadro de correntes relativas ao estudo e à prática do Direito Comparado na contemporaneidade ${ }^{1}$. De um lado, os que defendem o aporte das ciências sociais nos métodos de comparação, com proposições preexplicativas dos estudos a serem realizados, desvalorizando, muitas vezes, os estudos juscomparativos; de outro, os seguidores do Direito Comparado tradicional, entre os quais certamente me incluo, que buscam identificar as semelhanças e diferenças dos contextos jurídicos sem explicações prévias ou hipóteses de trabalho. O que se almeja é levantar os elementos em maior número possível que levem ao conhecimento, o mais completo, do outro contexto jurídico. Transpondo-se para as relações sociais, é como se ao conhecer-se alguém, as nossas ideias preconcebidas sobre a pessoa, toldassem o conhecimento dessa mesma pessoa. Recordo-me, a propósito, do pensamento de Krisnamurti, grande mestre hindu, sobre o conhecimento distorcido de uma simples árvore, visto que não a vemos como é, mas como imaginamos que ela seja.

\section{Zweigert e Kotz afirmam que o primeiro objetivo do Direito Com-} parado é o conhecimento. Entretanto, o Direito Comparado possuiria mais quatro objetivos específicos para os autores, quais sejam: prover material para o legislador; servir de instrumento para a interpretação; desempenhar seu papel na Universidade e finalmente auxiliar na constituição de uma "supranational unification of law"2.Zweigert e Kotz exauriram os objetivos desta ciência ou há ainda algo a acrescentar?

R. Acrescentaria um outro aspecto utilitário do Direito Comparado que é o da promoção da paz. O saudoso Professor Haroldo Valladão,

KISCHEL, 2016, pp. 907-926

ZWEIGERT; KOTZ, 1984, pp. 16-17. 
eminente mestre de Direito Internacional Privado e de Direito Comparado, disciplinas que se relacionam intimamente, enfatizava que um dos grandes objetivos do Direito Comparado é o aprofundamento da compreensão internacional para a busca da paz. O Professor René David, destacava, igualmente, este aspecto. Considero fundamental este objetivo. É da compreensão, do conhecimento do sistema do outro, em última análise, do outro, que se pode caminhar na busca da paz. Isso não significa que a meta de harmonização, alguns dizem, de unificação jurídica, passe por cima do respeito às identidades nacionais. Faz parte, precisamente, da compreensão, o reconhecimento de traços fundamentais das partes envolvidas que devem ser respeitados. Considero decepcionante e temerária a fixação de metas de harmonização jurídica ditadas, predominantemente, por interesses econômicos, descurando-se do respeito às identidades culturais das partes envolvidas.

\section{Para Rodolfo Sacco, o Direito Comparado deve ser compreendido} como um conhecimento crítico do direito3. Já para Horatia Muir Watt, o Direito Comparado, quando bem utilizado, é uma fonte inesgotável de interrogação, de reflexão e deve ser considerado como uma importante abertura para novas razões jurídicas 4 . O comparatista é um jurista inconformado com as formas prevalecentes da ciência em que ele está envolvido?

R. No meu entender, as posturas críticas e de interrogações sobre a realidade jurídica podem suceder aos estudos comparativos, mas não os condicionar. $\mathrm{O}$ grande mérito dos estudos juscomparativos é o de propiciar a compreensão, sem preconceitos, sem entendimentos prévios que distorçam a análise dos contextos jurídicos examinados, ótica, majoritariamente adotada pelos comparatistas aqui citados. Feita a comparação, dependerá de cada um identificar no Direito Comparado o tipo de contribuição que ele pode dar para o entendimento e até mesmo para a modificação da realidade jurídica.

SACCO, 1991. p.115

${ }^{4}$ WATT, 2000, p. 503 


\section{PESQUISA CIENTÍFICA}

1. A senhora foi orientanda por Denis Lévy, professor de direito público francês, na Universidade de Paris-Assas. Já em 1950, ele escrevia sobre temas ligados direito público comparado, notadamente o constitucional e o administrativo. É dele a influência que levou a senhora para o caminho do direito público comparado, tão raro entre os juristas brasileiros? Porque, no Brasil, tão poucos publicistas fazem efetivamente a comparação jurídica?

R. Aqui, também, as circunstâncias de vida preponderaram na escolha. Como professora, desde o nível do então chamado segundo grau, até o superior, sempre me interessei pela educação e por questões do Direito Constitucional e administrativo. Na França, ao mesmo tempo em que fazia o curso de doutorado em Paris II (Panthéon), fiz também, o mestrado em ciências da educação (Paris, V), na realidade não equivalente ao que seria o nosso mestrado, mas um curso de aprimoramento na área. Após conversas com o Professor Denis Lévy, a proposta de um estudo sobre o direito à educação na França e no Brasil vingou. Desta forma, o meu interesse pelo direito público comparado, notadamente o constitucional, foi tomando corpo. Posteriormente, tive o privilégio de trabalhar no Instituto de Direito Público e Ciência Política da Fundação Getúlio Vargas, inicialmente com o Professor Themístocles Cavalcanti, conforme mencionei acima, e depois, com o Professor Afonso Arinos de Melo Franco. Um, grande administrativista, o outro, emérito constitucionalista. O aprendizado que deles pude receber, somente fortaleceu o meu interesse pelos estudos no campo do direito público comparado, notadamente, do Direito Constitucional comparado.

\section{Ao analisar os argumentos de Direito Comparado usados pelo STF,} os professores Cecília Caballero (UFRJ) e Gabriel Lima Marques (UNIFAP) concluem, em recente estudo, que

[... a utilização do arcabouço alienígena pelo Supremo tem sido levada à frente por seus juízes de modo embaçado, incoerente e mais do que isso, descomprometido, tal fato acaba concorrendo tanto para a diminuição das potencialidades do mencionado material ${ }^{5}$.

LOIS; MARQUES, 2015 
Podemos levar essa importante e angustiante conclusão dos autores para o campo da pesquisa científica brasileira?

R. Foi a mesma conclusão a que chegamos, a Professora Adriana Vidal de Oliveira, também professora de Direito Comparado da PUC-Rio, e eu, no relatório do Brasil ao Congresso Internacional de Direito Comparado, de 2014, realizado em Viena. Após respondermos ao longo questionário elaborado pela Professora Marie Claire Ponthoreau para a seção de Direito Constitucional do referido Congresso sobre os recursos aos precedentes estrangeiros pelo juiz constitucional, com base em vasta e trabalhosa análise das ações constitucionais julgadas perante o Supremo Tribunal Federal, de 1988 a 2012 , constatamos que a convicção pessoal de cada juiz predomina na escolha dos precedentes estrangeiros, na maioria das vezes, sem esclarecimento sobre os critérios para a seleção dos mesmos. Tais precedentes são citados, a título de exemplo, para ilustrar e fortalecer a argumentação do juiz. Há, assim, uma escolha estratégica, visando a realçar a parte que reforça a tese judicial, sem uma preocupação maior de examinar outros aspectos que não se enquadrem nos objetivos aludidos.

3. Alguns autores, como Ran Hirschl, argumentam que há uma profunda diferença epistemológica entre a comparação em Direito Constitucional do final do século vinte e do início do século XXI. Como consequência, continua o autor, hoje é impossivvel estudar o Direito Comparado sem um forte componente de interdisciplinaridade intrinsecamente envolvido no processo, envolvendo o campo da Filosofia e, especialmente, a Ciência Política. Desta maneira, hoje seria mais apropriado falar em estudos constitucionais comparados e não Direito Constitucional comparado. ${ }^{6}$ Para a senhora, qual o papel da interdisciplinaridade no estudo do direito público comparado e, em especial, no Direito Constitucional comparado?

R. A interdisciplinaridade sempre foi a tônica nos estudos de Direito Comparado e de Constitucional Comparado, particularmente em relação aos aportes da Sociologia Política, da História, da Ciência Política e de tantas disciplinas que concorrem para iluminar os

${ }^{6}$ HIRSCHL, 2014, p. 151 
contextos constitucionais examinados. Se nas perspectivas dos estudos germânicos e italianos, esta interação não se dá tanto nos títulos das obras, mas nos textos que elas contêm, na ótica francesa os estudos de Direito Constitucional, e por maior razão, os de Direito Constitucional comparado, figura nos próprios enunciados dos manuais, que indicam tratar-se de estudos de Direito Constitucional e de instituições políticas. Sob o prisma anglo-saxão, tal interdisciplinaridade também, de há muito, é efetivada. Sabendo-se, pois, que a expressão "Direito Constitucional comparado" pressupõe, por entendimento consolidado, esta interdisciplinaridade, no meu entender, ela continua válida para indicar o amplo espectro que as suas investigações recobrem. Isso não significa que a expressão « estudos constitucionais comparados " não tenha o seu lugar, mas certamente ela é mais imprecisa e fluida do que a anterior. O principal, penso eu, é que haja correspondência entre o título e a análise desenvolvida. Um texto que focalize apenas aspectos históricos ou sociológicos não será, certamente, um texto de Direito Constitucional comparado ou um estudo comparado sobre matéria constitucional. Tive a oportunidade de abordar essa questão no texto "Nota sobre as dimensões do Direito Constitucional comparado", publicado no número 14 da Revista Direito, Estado e Sociedade do Departamento de Direito da PUC-Rio (www.jur.puc-rio.br/revistades/index.php/revistades/article/download/353/326) ${ }^{7}$

\section{FUTURO}

1. Para a senhora, porque um jovem pesquisador hoje deve dedicar seu tempo a estudar uma disciplina que sequer é citada pelas Diretrizes Curriculares Nacionais do Curso de Graduação em Direito, como o Direito Comparado? Ele não corre o risco de se ver sem espaço na academia brasileira?

R. A meu ver, a pesquisa jurídica não deve ficar limitada aos ramos do Direito, isto é, àqueles positivados e que regulam determinadas áreas da atividade social. São precisamente as disciplinas parajurídicas, isto é, auxiliares do estudo do direito, que propiciam o estudo amplo dos mesmos ramos em seus múltiplos desdobramentos. São disciplinas auxiliares, ou parajurídicas, o direito romano, a história

TAVARES, 1999 
do direito, a sociologia jurídica, o Direito Comparado e muitas outras. Um pesquisador que se limitasse ao estudo dos ramos positivados certamente ficaria muito limitado em seu saber jurídico e aí sim, poderia correr o risco de ficar sem espaço na academia brasileira. Seu universo reduzido dificilmente lhe permitiria competir com outros pesquisadores, que, ao contrário, houvessem ampliado a sua área de conhecimento, permitindo-lhes galgar outros patamares acadêmicos nacionais e estrangeiros.

2. A senhora é considerada um exemplo de pesquisadora e professora de Direito Comparado, ao mesmo tempo é uma inspiração para muitos jovens estudantes. O que é, para a senhora, um bom comparatista? E o que é preciso fazer para sê-lo?

R. Não me considero como tal. Talvez esta afirmativa decorra do entusiasmo que sempre imprimi nas minhas aulas, fascinada pela riqueza dos aportes do Direito Comparado, seja na vida acadêmica, seja na vida pessoal, com o amadurecimento cultural que ele propicia. Procurei transmitir esse entusiasmo aos alunos nesses 40 anos de magistério da disciplina. Em seu decorrer, percebi, de um lado, que é fundamental a atualização constante dos dados, de diversas ordens, inclusive interdisciplinar, e que constituem a base dos estudos juscomparativos. De outro, a importância de serem os estudos comparativos empreendidos sem juízos de valor. Os sistemas jurídicos (em sentido amplo ou no restrito) não são melhores nem piores. São diferentes. A compreensão de suas peculiaridades numa disposição de total isenção é necessária para a confiabilidade desses estudos. Não se trata de procurar elementos na comparação para justificar opiniões pessoais. Trata-se de efetuar um levantamento, o mais exato possível, que confira uma base confiável à comparação.

3. O Direito já passa há alguns anos pelo inevitável processo de internacionalização/ transnacionalização. Como o Direito Comparado enfrenta esse importante desafio para os pesquisadores no campo do direito público?

R. A intensificação dos movimentos globais e de circulação de pessoas levou a uma valorização dos estudos de Direito Comparado, entendido este como um instrumento valioso para a harmonização 
dos sistemas, tendo em vista, sobretudo, as metas de organismos regionais e internacionais. É usual que nas publicações o Direito Comparado figure ao lado do direito internacional e global. Entretanto, como acima notamos, os objetivos de harmonização jurídica não devem levar a que as identidades jurídicas nacionais sejam ignoradas. Ao contrário. Elas devem ser consideradas sobretudo para o conhecimento da viabilidade de certas aproximações entre grupos. O notável crescimento dos movimentos migratórios em nosso século constitui, sem dúvida, um desafio para a colocação em prática, por parte dos comparatistas, daqueles objetivos ínsitos à disciplina, acima referidos.

\section{REFERÊNCIAS}

HIRSCHL, Ran. Comparative Matters: The Renaissance of Comparative Constitutional Law. Oxford University Press: Nova York, 2014.

KISCHEL, Uwe. La méthode en droit comparé. L'approche contextuelle. Revue Internationale de Droit Comparé, v. 68, n. 4, 2016.

LOIS, Cecília Caballero; MARQUES, Gabriel Lima. O Supremo Tribunal Federal e o Argumento de Direito Constitucional Comparado: Uma Leitura Empírica a partir dos Casos de Liberdade de Expressão no Brasil. Direito, Estado e Sociedade. n. 47, 2015.

SACCO, Rodolfo. La comparaison juridique au service de la connaissance du droit. Economica: Paris, 1991.

TAVARES, Ana Lúcia de Lyra. Nota sobre as dimensões do Direito Constitucional comparado. Direito, Estado e Sociedade. n. 14, 1999.

WATT, Horatia Muir. La fonction subversive du droit comparé. Revue Internationale de Droit Comparé, v. 52, n. 3, 2000.

ZWEIGERT, Konrad; KÖTZ, Hein. An Introduction to Comparative Law. Oxford University Press: Nova York, 1987. 